\title{
OPEN Unconventional effects of long-term storage of microwave-modified chicken egg white lysozyme preparations
}

\author{
Grzegorz Leśnierowski ${ }^{\bowtie}$, Tianyu Yang ${ }^{\bowtie}$ \& Renata Cegielska-Radziejewska
}

Thermal modification is an effective method that induces significant expansion of the antimicrobial properties and other valuable properties of chicken egg white lysozyme. In our latest research, a new innovative method of enzyme modification was developed, in which microwave radiation was used as an energy source to process liquid lysozyme concentrate (LLC). After modification, highquality preparations were obtained. However, long-term storage in a concentrated form initiated various processes that caused darkening over time and could also lead to other significant changes to their structure and, consequently, to their functional properties. This necessitated multidirectional research to explain this phenomenon. This paper presents the results of research aimed at assessing the physicochemical changes in the properties of microwave-modified lysozyme in the form of a liquid concentrate after long-term storage under refrigeration conditions. The assessment also considered the conditions under the acidity of the modifying medium and the duration of the microwave modification. The analysis showed that the values of the basic parameters determining the quality and usefulness of the modified enzyme significantly improved during long-term storage of the preparations. The greatest changes were observed in the preparations modified for the longest time and in the most acidic environment (process time $260 \mathrm{~s}, \mathrm{pH} 2.0$ ), the number of oligomers under these conditions increased by $18 \%$ after 12 months of holding, and the surface hydrophobicity increased by as much as $31 \%$. In addition, microbiological tests showed that the preparations of microwavemodified lysozyme had an effect on gram-positive bacteria as well as on gram-negative, and this effect was significantly enhanced after 12 months. The results confirm that LLC modification with microwave radiation is a highly efficient method to prepare high-quality and high utility potential lysozyme. Notably, an interesting and important phenomenon was the observation of the unconventional behaviour of the preparations during their long-term storage, which increased their utility potential significantly.

Native lysozyme derived from hen egg white (EC3.2.1.17) is a highly functional monomeric enzyme protein composed of 129 amino acids with highly effective antibacterial activity. This enzyme is often used as a model protein in numerous scientific studies and has aroused increasing attention for practical use due to its multiple valuable properties. The food industry is particularly interested in it, especially since it was recognized by the $\mathrm{WHO} / \mathrm{FDA}$ as safe for the production and preservation of food ${ }^{1}$. This area of activity primarily uses its antibacterial effect, which is based on the destruction of the $\beta$-1,4-glycosidic bond found in the structure of the cell wall of many bacteria. However, this mainly applies to gram-positive bacteria because gram-negative bacteria are resistant to such action because this glycosidic bond is protected by the specific structure of their wall ${ }^{2}$. However, the spectrum of the enzyme's antibacterial activity can be significantly expanded as a result of modifications leading to changes in the protein structure that cause its oligomerization and an increase in surface hydrophobicity ${ }^{3,4}$. The modified lysozyme also has antiviral ${ }^{5}$ and antifungal ${ }^{6,7}$ properties and stimulates the appropriate cells of the body to produce various bioactive compounds to obtain antitumour activity ${ }^{4,8}$. According to the latest reports, by stimulating the formation of interferon- $\beta^{4}$, the enzyme may be an effective agent against the SARS-Cov- 2 virus and thus help fight COVID-199,10. This comprehensive potential of lysozyme, especially the modified form, means

Department of Food Safety and Quality Management, Faculty of Food Science and Nutrition, Poznan University of Life Sciences, Wojska Polskiego 31, 60-624 Poznan, Poland. ${ }^{\bowtie}$ email: grzegorz.lesnierowski@up.poznan.pl; tianyu. yang@up.poznan.pl 


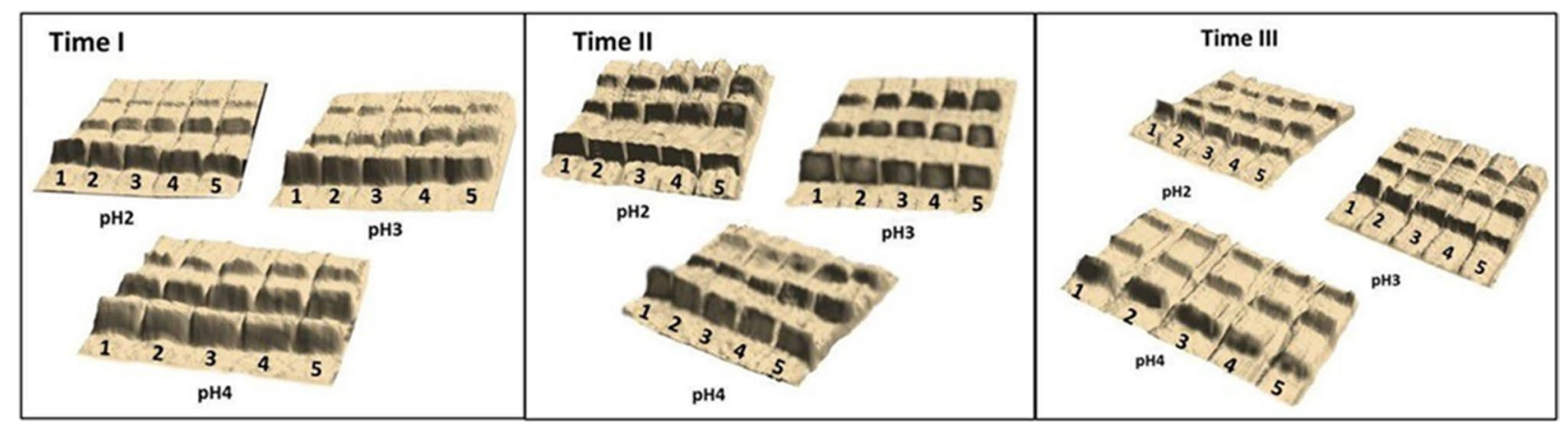

Figure 1. Electrophoretic images (3D) of lysozyme modified by microwave radiation: Time I-directly after modification, Time II-after 6 months of storage, Time III-after 12 months of storage, 1-5-modification time $180,200,220,240$, and 260 s respectively.

that extensive research into new methods of its modification is being carried out to deepen the knowledge about modification techniques and improvements and obtain the most effectively modified form, which will enable the wide practical application of the product. Among the known types of lysozyme modification methods, the best known and most used is the group of thermal methods, which includes one of the newest methods, the so-called microwave method, in which the energy necessary to modify the enzyme comes from microwave radiation ${ }^{11,12}$. It has been shown that a high-quality modified enzyme is obtained under properly selected process conditions, and the method has many advantages including the ease of the process and its control, short modification time, and low cost. In addition, this technique allows for the enzyme to be modified at several times higher concentrations in the solution than in other thermal methods, which makes the process very efficient. Therefore, commercial lysozyme produced as a liquid concentrate (LLC) in which the concentration of lysozyme is approximately $20 \%$ can be used for modification. The final product is in the form of a liquid concentrate, which facilitates further practical use. However, it has been observed that some changes occur during storage of the final products, which are manifested in a darkening colour. Therefore, it is important to analyse this phenomenon. The main objective of this study was to evaluate changes in selected physicochemical properties of microwave-modified lysozyme stored in the form of a liquid concentrate for 12 months under refrigeration. The stored preparations were also subjected to tests to assess their antibacterial activity.

\section{Results and discussion}

The research presented in this paper is a continuation of work on a new method that uses microwave radiation as an energy source for thermal modification of lysozyme in an oxidizing environment. The results of previous studies have shown that this kind of energy combined with an oxidation reagent effectively promotes the formation of a significant amount of the oligomeric form of lysozyme by increasing its surface hydrophobicity, which is closely related to the creation of its new properties, including the development of its antimicrobial potential ${ }^{11,12}$. By examining a wide range of different factors influencing the effect of this type of modification, it was shown that the enzyme was best modified in a strongly acid $(\mathrm{pH} \mathrm{2,3}$, and 4) oxidizing environment (addition of hydrogen peroxide), with a microwave energy power of $270 \mathrm{~W}$. In addition, the modification duration was also important, typically from 180 to $260 \mathrm{~s}$.

To reduce the negative influence of high temperature on the modified enzyme, resorcinol is usually used as a protective substance ${ }^{13}$, so this substance was also used in this case. The modification effect was influenced by the type of starting material used, which is commercially in a dried form but is now increasingly produced in the form of a liquid concentrate (LLC). It has been shown that the modification efficiency using LLC, even with enzyme content reduced from 20 to $10 \%$, can significantly increase compared with that obtained using a dried preparation whose concentration in the modified solution was at most $5 \%$. This is of great importance when the method is used for the commercial production of a modified enzyme because a larger amount of the preparation is obtained, and its liquid concentrated form is more convenient to use $e^{4,13,14}$. However, during the storage of these preparations, a unique phenomenon of changing properties was observed. With storage time, the samples became darker, and their hydrolytic activity changed. Therefore, further studies on this modification method included assessment of the changes in the most important physicochemical properties, such as the degree of oligomerization, and changes in the hydrophobic surface and hydrolytic activity after 6 and 12 months of storage at $4-6{ }^{\circ} \mathrm{C}$. The colour of the concentrate was also examined, and microbiological tests were performed. The most important results of these studies have been analysed and are presented in this paper.

The modification of the enzyme was performed according to the procedures outlined in the "Materials and methods" section. The obtained data were collected and subjected to statistical analysis, and the observed correlations and dependencies are presented in the following charts. The influence of the tested factors, i.e., the effects of storage time on the samples modified for 180 to $260 \mathrm{~s}$ at $\mathrm{pH} 2.0,3.0$, and 4.0, on the degree of enzyme oligomerization is graphically illustrated with both 3D images of conducted electrophoresis (Fig. 1) and graphs obtained during data analysis (Fig. 2).

The analysis shows that each of these factors significantly influenced the final modification effect. Oligomerization was most intense in the most acidic environment $(\mathrm{pH}=2.0)$, and the duration of the modification 


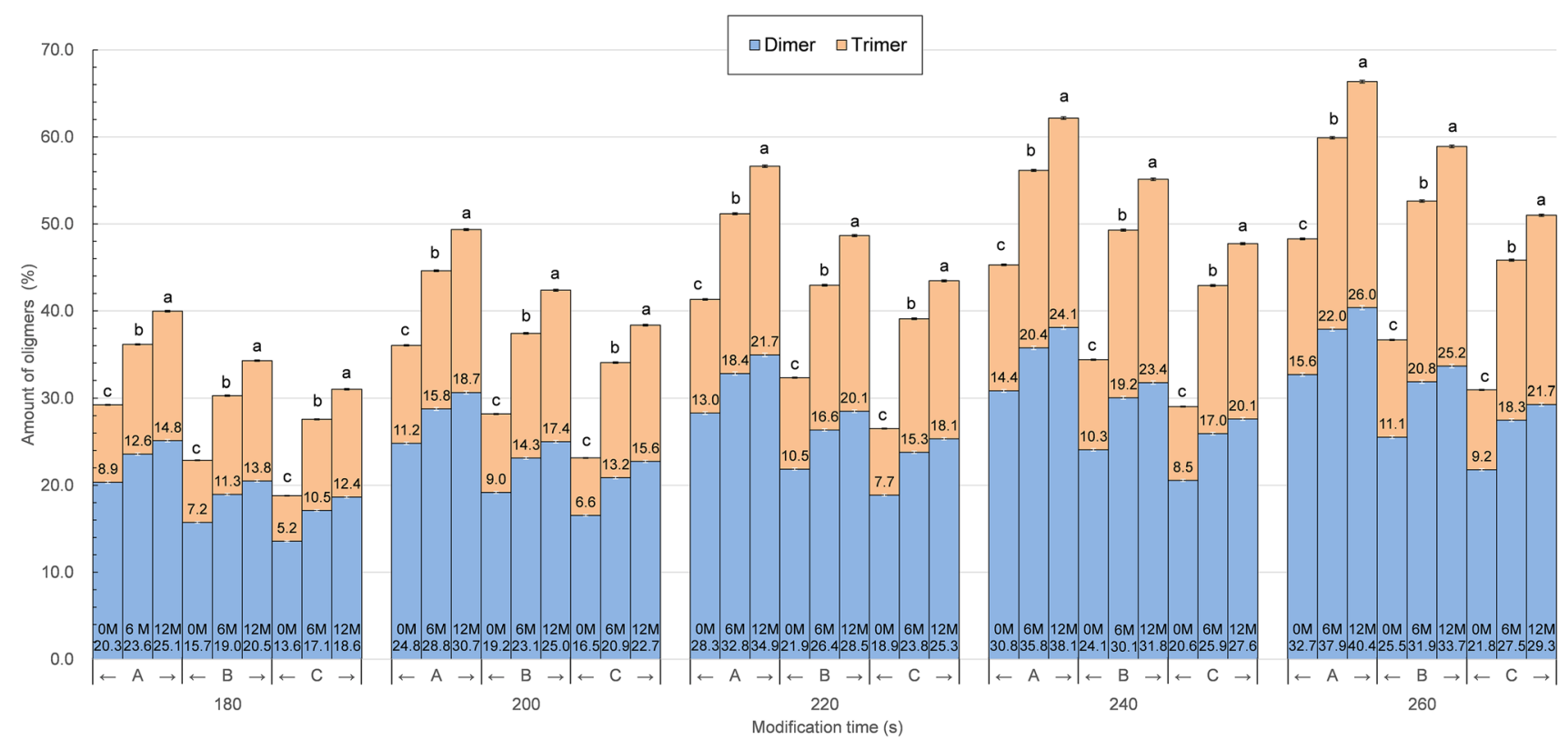

Figure 2. Characterization of the oligomeric properties of an LLC with the modified process, cold storage time, and $\mathrm{pH}$ (storage time: 0, 6, and 12 months, time of modification: 180, 200, 220, 240, and $260 \mathrm{~s}, \mathrm{pH}: \mathrm{A}-2.0, \mathrm{~B}-3.0$, and C-4.0). (a-c) Different letters on the bars denote a significant difference in the means at $\mathrm{p} \leq 0.05$. The top of the bar-trimer. The bottom of the bar-dimer.

intensified this process; the highest effect was always recorded for the 260 -s process. An extremely interesting phenomenon was the further intensive oligomerization of the enzyme during its refrigerated storage. Immediately after modification, under the most favourable conditions (time $260 \mathrm{~s}, \mathrm{pH} 2.0$ ), $48.3 \%$ oligomers were obtained, including $32.7 \%$ dimer and $15.6 \%$ trimer. A similar effect was achieved using other thermal methods ${ }^{13,14}$. However, in the case of the microwave method, the amount of oligomers increased during the storage of samples; after 6 months, it was already 59.9\% (37.9\% dimer and 22.0\% trimer), and after 12 months, it was as high as $66.4 \%$ ( $40.4 \%$ dimer and $26.0 \%$ trimer). With higher $\mathrm{pH}$ values and shorter modification times, these values were lower but the growth rate during storage was similar. Such unconventional behaviour of the modified lysozyme requires additional research aimed at explaining this interesting phenomenon. It will also be important to try to assess the changes that could occur during similar retention of lysozyme modified by other methods but left in a liquid form. The conducted research shows that the key seems to be the form of storage of ready-made preparations, and the modification method only initiates modification processes and affects their effectiveness during the modification process. The research on the mechanism of thermal denaturation of lysozyme shows that protein unfolding resulting from this process causes, among others, the destruction of disulphide bonds, the appearance of free sulfhydryl groups, and the exposure of tryptophan residues to the surface of the molecule, which in turn leads to an increase in the surface hydrophobicity of the enzyme $e^{7,15,16}$. Such structural changes in the lysozyme molecule cause its oligomerization with the simultaneous appearance of new antibacterial activity (different from hydrolytic activity) directed mainly against gram-negative bacteria, according to Ibrahim et al. ${ }^{3,6,17}$. On the other hand, the observations of Thomas et al. (1998) show that long-term oxidation of lysozyme in an acidic environment causes its dimerization, and the effect of the process is intensified when a previously thermally modified enzyme is used ${ }^{18}$. In numerous of our laboratory works, we observed similar phenomena ${ }^{4,11,14,19,20}$, which we used in the development of the enzyme modification method presented in this paper. Probably, the combination of all these factors contributed to such an unconventional final effect of storing microwave-modified lysozyme preparations in a liquid oxidizing environment. It can be expected that this effect, resulting in an unexpected increase in the proportion of oligomers and an increase in surface hydrophobicity, should increase the utility value of the preparations because of the greater oligomers and greater hydrophobic surface in the modified enzyme, the greater their antimicrobial activity.

In contrast, another important physicochemical property, the hydrolytic activity, decreased significantly with increasing storage time. According to Fig. 3, the hydrolytic activity was $77.9 \%$ to $30.1 \%$ just after modification and $65.2 \%$ to $21 \%$ that of the natural lysozyme monomer after one year of cold storage. Unlike in the case of oligomerization, the highest decrease in the hydrolytic activity was observed when the $\mathrm{pH}$ of the environment was the lowest ( $\mathrm{pH} 2.0$ ), and the modification and storage time were the longest ( $260 \mathrm{~s}$ and 12 months, respectively). Nevertheless, this is not a negative change for the exploration of the potential of lysozyme. Many studies have shown that enzyme activity significantly declines with structural changes in lysozyme when any method is used to stimulate the potential of lysozyme, which is accompanied by the emergence of higher new antimicrobial activity. This newly obtained activity in combination with the remaining catalytic activity creates a completely new antimicrobial potential of the enzyme, so-called total antibacterial activity (TAA), which has a broader spectrum of antimicrobial activity than that of the natural monomer and is also effective against gram-negative bacteria $^{4,14,21-23}$. 
$\mathrm{pH} 2$

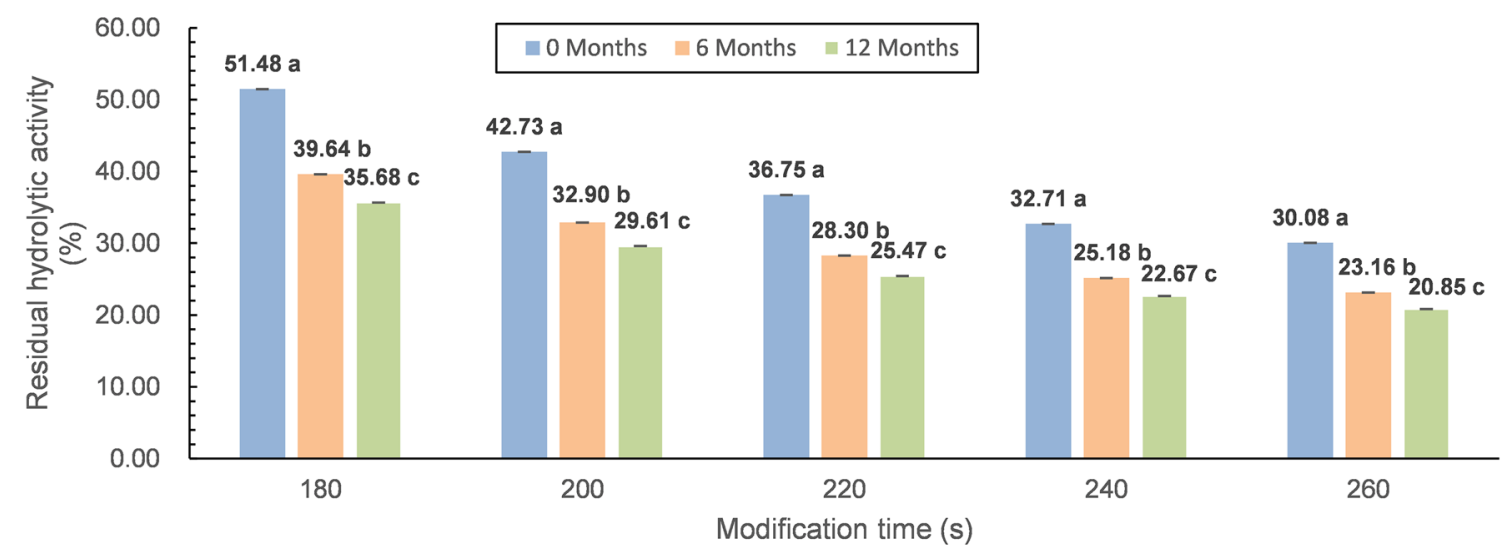

(a)

\section{$\mathrm{pH} 3$}

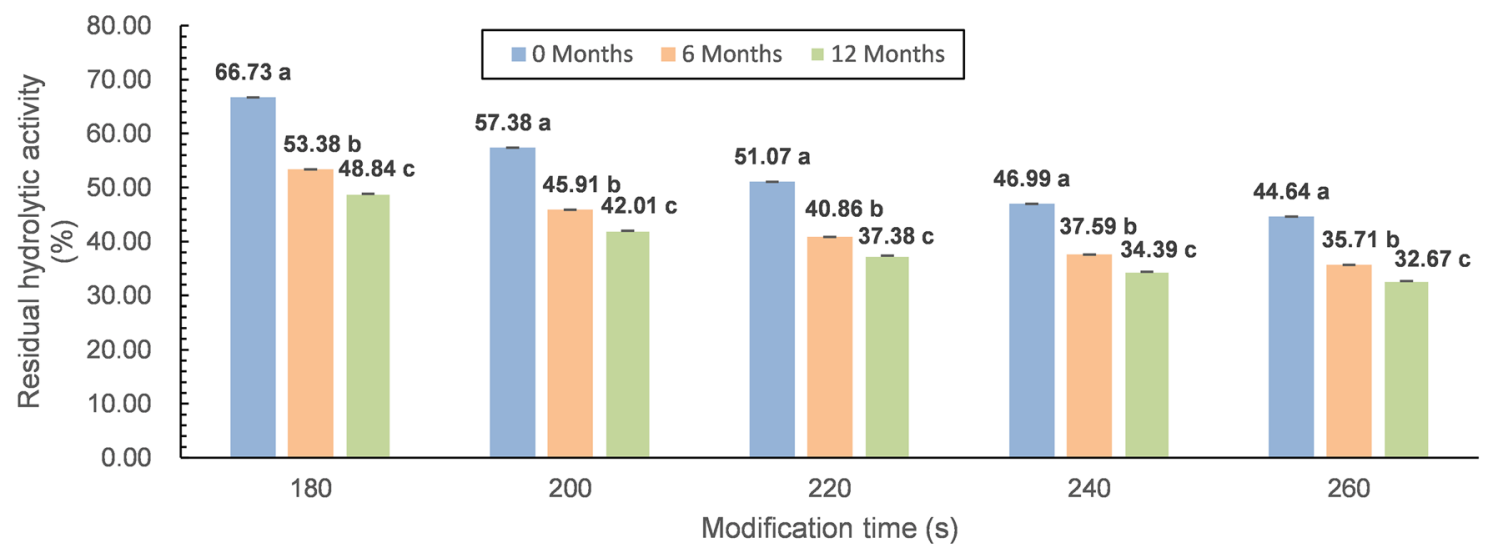

(b)

$\mathrm{pH} 4$

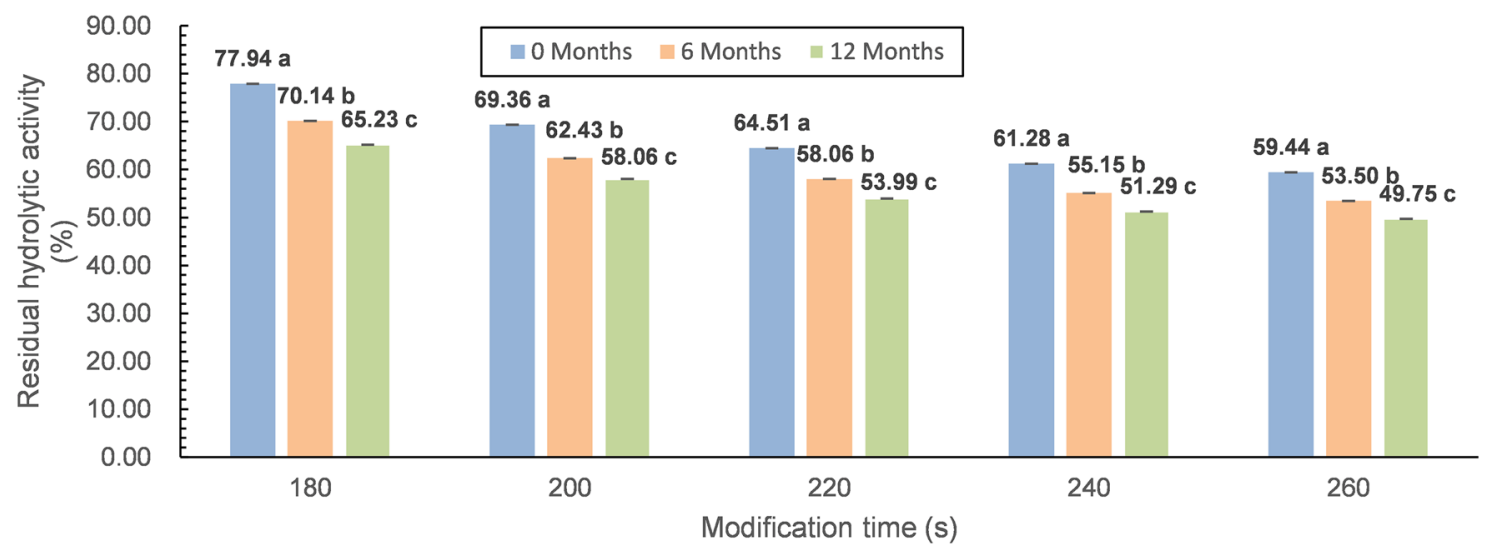

(c)

Figure 3. Graphical interpretation of the storage changes of the hydrolytic activity of microwave-modified lysozyme preparations (a- $-\mathrm{pH} 2, \mathbf{b}-\mathrm{pH} 3, \mathbf{c}-\mathrm{pH}$ 4). Storage times: 0,6 , and 12 months. Time of modification: $180,200,220,240$, and $260 \mathrm{~s}$. (a-c Different letters on the bars denote a significant difference in the means at $\mathrm{p} \leq 0.05-$ separately considered for each modification time). 
Although the formation mechanism and principle of new activity are not yet understood completely, one of the factors determining the expansion ability of lysozyme's new antibacterial spectrum is the oligomer content $^{3,24,25}$. The greater the oligomer content, especially the dimer content, the greater the range of strains that were affected by lysozyme. The change in the hydrophobicity of the lysozyme preparation is generally considered to be one of the most important properties in the new ability of the lysozyme. It was proven that more new antibacterial properties are obtained when the surface hydrophobicity of lysozyme is significantly increased because the modification of lysozyme results in a change in the lysozyme secondary structure and moves the internal location of the hydrophobic group to the surface. This exposure hydrophobicity could increase the binding capacity between lysozyme and the bacterial membrane, increasing the new antibacterial activity ${ }^{3,26}$. Hence, hydrophobicity has an important reference value in judging the changes in the enzyme preparation during storage. By analysing the changes in the hydrophobicity of the lysozyme after modification and during storage (Fig. 4), we noticed the same relationships as those observed for oligomerization; the hydrophobic surface of lysozyme changed obviously during the modification process and long-term storage. With the increase in the degree of enzyme modification (an increase in the amount of oligomers), the surface hydrophobicity also increased, which was consistent with the results of previous studies on the modification of lysozyme using the microwave method $^{11}$. This trend is confirmed by the graphic interpretation of the results presented in Fig. 4, which clearly indicates that the lower the $\mathrm{pH}$ was and the longer the modification and storage time were, the more favourable the changes in the hydrophobic surface were. The preparations that were modified for $260 \mathrm{~s}$ at $\mathrm{pH} 2.0$ and stored for 12 months under refrigeration were characterized by the highest surface hydrophobicity of over $72 \%$.

In the process of storing samples in a cold store, changing their colour was the most easily observed property. Various factors such as storage time, modification time, and $\mathrm{pH}$ of the modification process are related to the colour of the lysozyme preparation (Fig. 5). Before modification, the lysozyme solutions were colourless. The modification process caused their darkening, and the intensity of the observed colour changes depended on the conditions of the modification. The cooling storage time has intensified this phenomenon. It was illustrated by changes in spectrophotometrically measured extinctions, the value of which increased from 0.0 for unmodified samples to more than 0.3 for modified preparations stored for 12 months. Statistical analysis showed that, in addition to the storage time, the factors significantly influencing such colour change include a longer time of enzyme modification and a lower $\mathrm{pH}$ value of the environment in which it was modified. The cause of such deep changes in the colour of the modified lysozyme is not yet known; therefore, this phenomenon requires additional research. The colour change did not have a significant effect on the tested physicochemical characteristics of the preparations, but it was correlated with them. It is a visible indicator of changes taking place in the modified lysozyme preparations, which can be used to monitor its quality during refrigerated storage.

The analysis of the obtained results shows that the modification of LLC by the microwave method promotes a higher degree of oligomers and increases the surface hydrophobicity in the low-pH modified environment and with longer process time and maintains a significant increasing trend in the degree of oligomers and surface hydrophobicity during a long period of storage (one year). The crucial information resulting from these studies is the fact that the long-term storage of the modified lysozyme improved the desired effects of the original microwave-modified enzyme, increasing its practical utility. Under optimal conditions of a $\mathrm{pH}$ of 2.0 and a modification time of $260 \mathrm{~s}$, the proportion of modified lysozyme reached $66.4 \%$ (including $40.4 \%$ dimer and $26.0 \%$ trimer), and the surface hydrophobicity increased to $72 \%$. Although the hydrolytic activity showed a negative change with increasing cold storage time, presumably it was accompanied by the new activity. According to previous studies, lysozyme modifications extend the spectrum of the enzyme's antibacterial action and its TAA is always increased. It has been confirmed that the increase in TAA is characterized by more oligomers and higher hydrophobicity ${ }^{4,7,27}$. Considering the research results, it can be hypothesized that long-term storage of microwave-modified lysozyme under refrigeration conditions $\left(4-6{ }^{\circ} \mathrm{C}\right)$ may significantly enhance its antibacterial potential and significantly expand the spectrum of its action in addition to very favourable changes in the physicochemical properties. The results of simple microbiological tests carried out on selected lysozyme preparations and bacteria presented in Table 1 verify this hypothesis.

These results clearly show that the modification of LLC with microwave radiation significantly increased the antimicrobial potential of the enzyme. The unmodified lysozyme at a concentration of $0.5 \%$ was effective only against gram-positive (+) Micrococcus luteus bacteria, whereas it also showed activity at the same concentration against gram-negative (-) Pseudomonas fluorescens, Pseudomonas fragi, Escherichia coli, and Proteus mirabilis bacteria directly after modification. Even more interesting results were obtained for the same modified preparations when tested after a 12-month storage period. Growth inhibition of all tested bacterial strains was obtained with a $0.0625 \%$ enzyme concentration in the suspension. Such positive test results confirmed the need for planning and carrying out extensive microbiological research in this area to reveal the previously unknown, unconventional phenomenon of the increasing antimicrobial potential of the modified enzyme during storage. These results will be disseminated soon.

\section{Conclusion}

The presented results prove that microwave radiation can be an excellent source of energy to produce high-quality modified lysozyme preparations and that the storage of these preparations under refrigeration conditions gives unexpectedly positive effects. The unconventional behaviour of this microwave-modified enzyme has been demonstrated, revealing beneficial changes in its basic physicochemical properties and enhanced antibacterial potential. Due to its unique advantages, this simple and inexpensive method can be an effective tool in the industrial production of these attractive preparations. However, such an unconventional behaviour of microwave-modified lysozyme requires additional research aimed at explaining this interesting phenomenon as well as attempting to assess the changes that could occur during similar storage of lysozyme modified by other methods. 
$\mathrm{pH} 2$

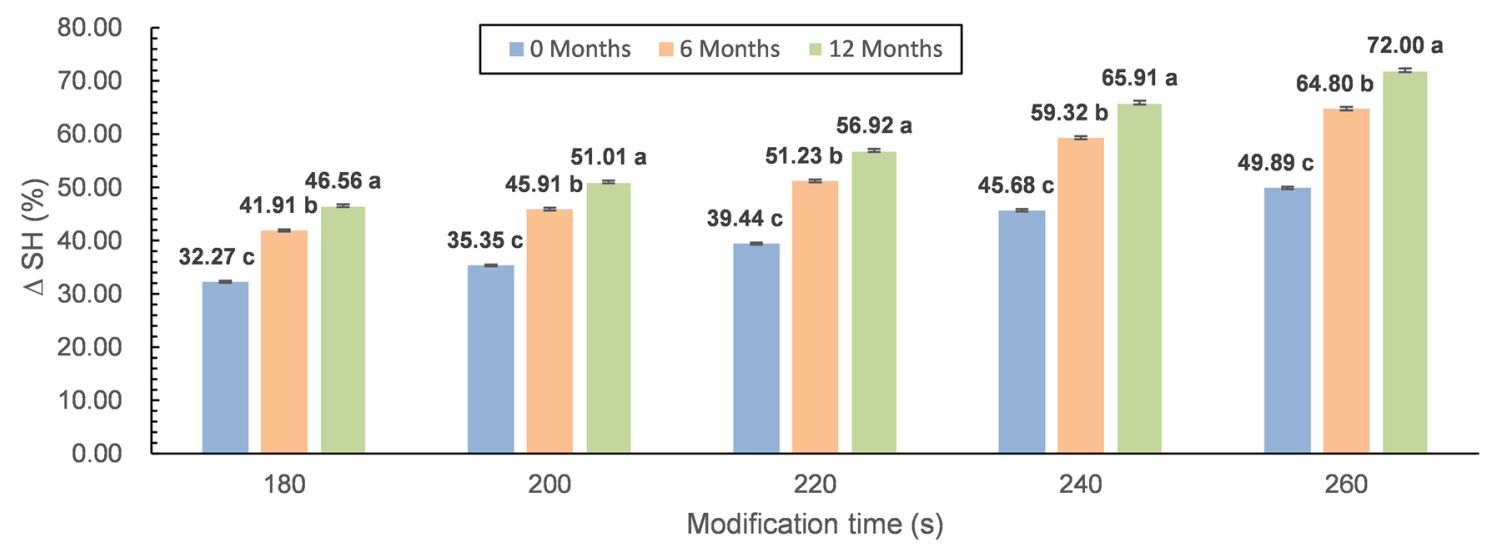

(a)

$\mathrm{pH} 3$

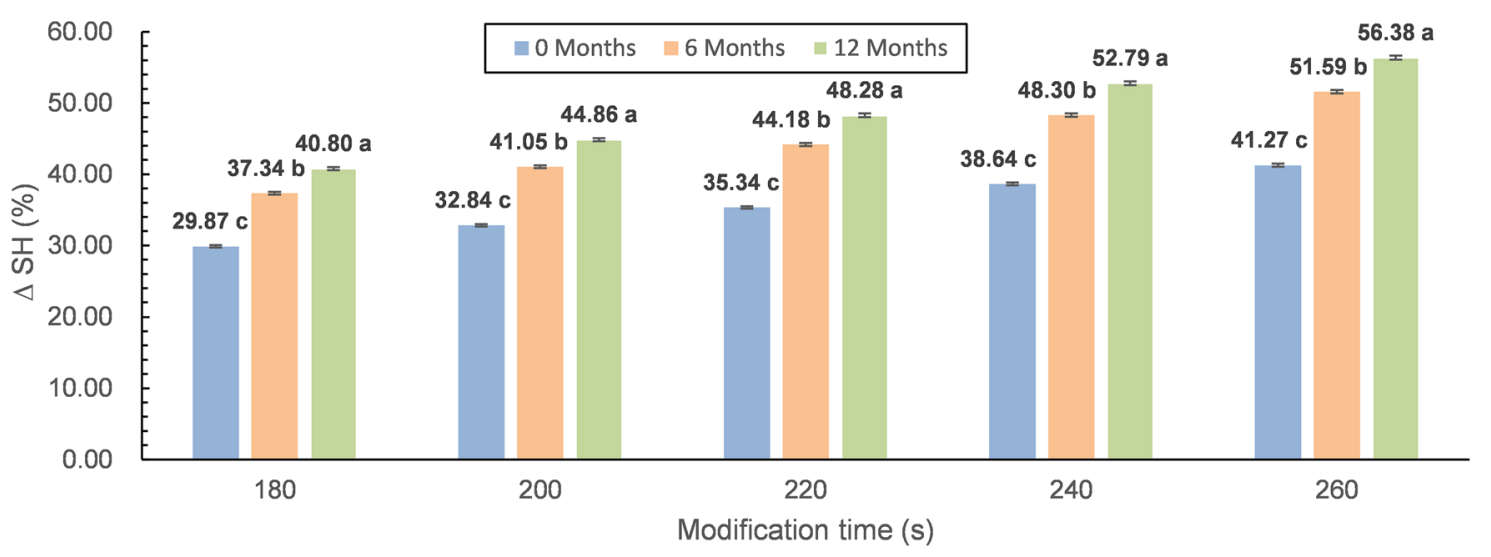

(b)

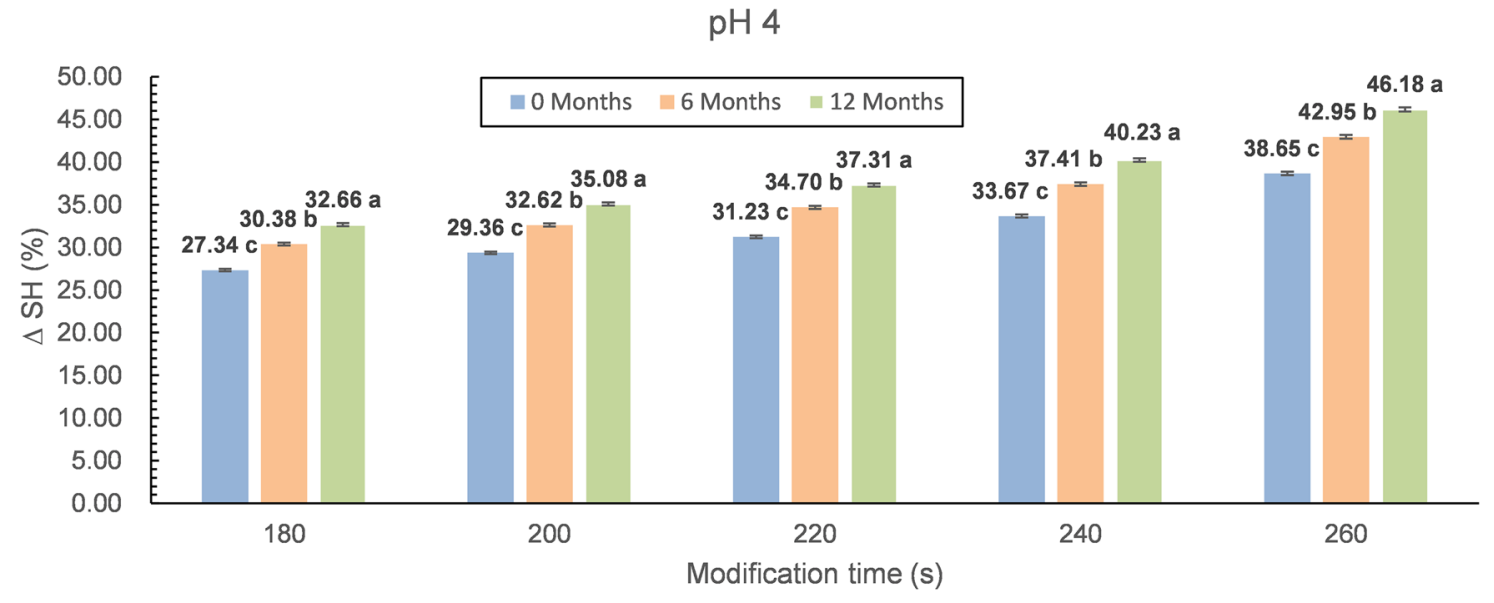

(c)

Figure 4. Graphical interpretation of the storage changes of the hydrophobic surface of microwave-modified lysozyme preparations $(\mathbf{a}-\mathrm{pH} 2, \mathbf{b}-\mathrm{pH} 3, \mathbf{c}-\mathrm{pH} 4)$. Storage times: 0,6 , and 12 months. Time of modification: $180,200,220,240$, and $260 \mathrm{~s}$. ( ${ }^{\mathrm{a}-\mathrm{c}}$ Different letters on the bars denote a significant difference in the means at $\mathrm{p} \leq 0.05$-separately considered for each modification time). 
pH 2

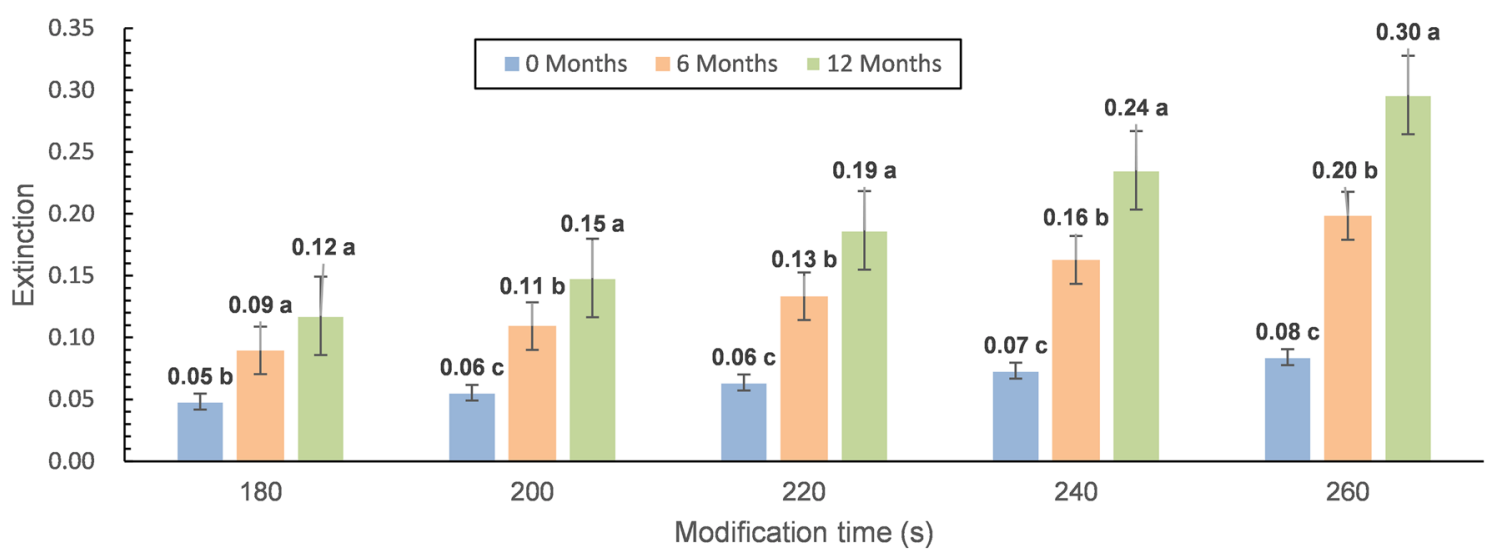

(a)

$\mathrm{pH} 3$

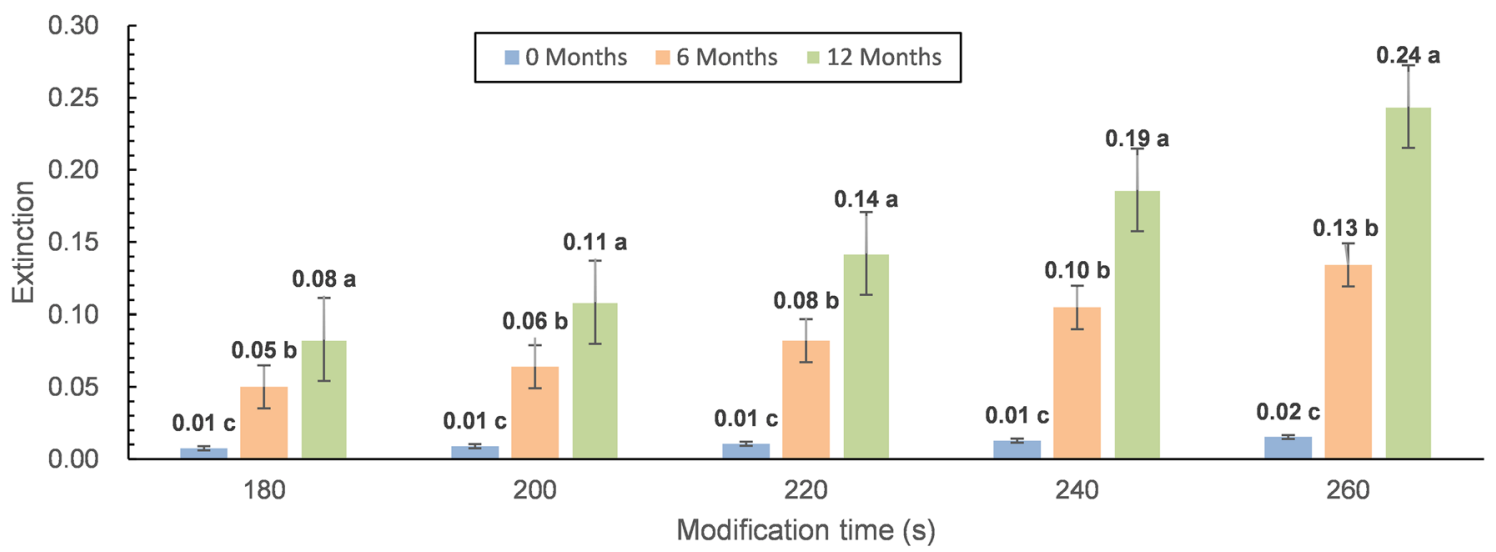

(b)

pH 4

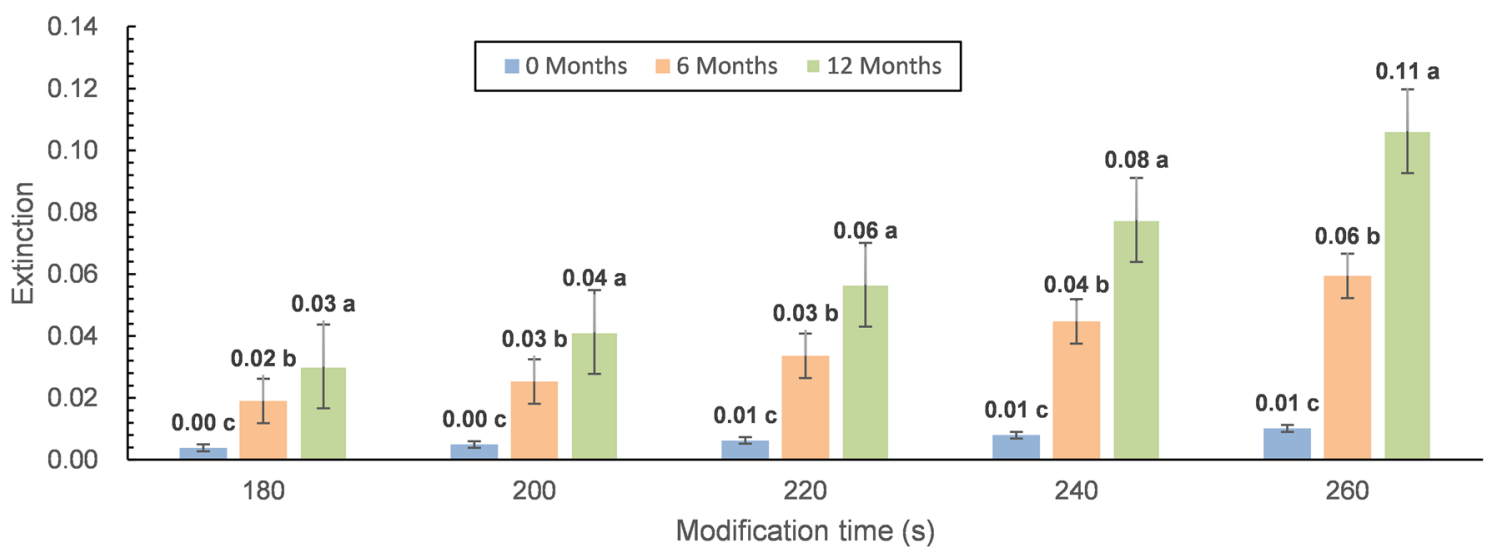

(c)

Figure 5. Graphical interpretation of the storage changes in the colour of microwave-modified lysozyme preparations ( $\mathbf{a}-\mathrm{pH} 2, \mathbf{b}-\mathrm{pH} 3, \mathbf{c}-\mathrm{pH}$ 4). Storage times: 0, 6, and 12 months. Time of modification: 180, 200, 220,240 , and $260 \mathrm{~s}$. $\left({ }^{\mathrm{a}-\mathrm{c}}\right.$ Different letters on the bars denote a significant difference in the means at $\mathrm{p} \leq 0.05-$ separately considered for each modification time). 


\begin{tabular}{|l|l|l|l|l|l|l|}
\hline \multirow{2}{*}{ Sample } & $\begin{array}{l}\text { Lysozyme concentration inhibiting } \\
\text { bacterial growth in suspension }\end{array}$ & $\begin{array}{l}\text { Gram (+) } \\
\text { bacteria }\end{array}$ & \multicolumn{3}{|l|}{ Gram (-) bacteria } \\
\hline \multirow{2}{*}{ Lysozyme (LLC) } & & $\begin{array}{l}\text { Micrococcus } \\
\text { luteus }\end{array}$ & $\begin{array}{l}\text { Escherichia } \\
\text { coli }\end{array}$ & $\begin{array}{l}\text { Proteus } \\
\text { mirabilis }\end{array}$ & $\begin{array}{l}\text { Pseudomonas } \\
\text { fluorescens }\end{array}$ & $\begin{array}{l}\text { Pseudomonas } \\
\text { fragi G(-) }\end{array}$ \\
\hline \multirow{2}{*}{ Lysozyme (directly after modification) } & 0.5000 & + & - & - & - \\
\cline { 2 - 7 } & 0.0625 & + & + & - & + & + \\
\hline \multirow{2}{*}{ Lysozyme (stored for 12 months) } & 0.5000 & + & - & - & - \\
\cline { 2 - 7 } & 0.0625 & + & + & + & + & + \\
\hline
\end{tabular}

Table 1. Microbiological test of lysozyme antibacterial activity against selected gram-positive (+) and gramnegative (-) bacteria.

Nevertheless, the results of the presented research reveal new important knowledge about lysozyme, especially its unconventional behaviour during long-term storage after microwave modification and are of unquestionable importance for its practical use in food and other industries, and in medicine, veterinary and pharmacology.

\section{Materials and methods}

Material. The liquid monomer lysozyme concentrate (LLC) was produced and provided by SACCO Poland company, and the protein content was over $94 \%$. The LLC was distributed as a $20 \%$ concentrate high chemical purity preparation and $8800 \mathrm{U} / \mu \mathrm{L}$ hydrolytic activity.

Microwave modification of LLC. Prior to modification, the lysozyme concentration in LLC was reduced to $10 \%$ by diluting the concentrate with distilled water. The $\mathrm{pH}$ of the resulting solution was adjusted to 2.0, 3.0 , and 4.0 with hydrochloric acid or sodium hydroxide and a protective agent (1.5\% benzodiazepine) against enzyme denaturation at high temperature. Hydrogen peroxide was added to each sample as an additional modifier to obtain a concentration of $1.5 \%$. Ten millilitres of each prepared monomer solution $(\mathrm{pH} 2,3$, and 4$)$ was modified in sealed pressure containers with microwave radiation of $270 \mathrm{~W}(2.45 \mathrm{GHz})$ for $180,200,240$, and $260 \mathrm{~s}$ in a microwave integrator (Sharp microwave integrator, model R-978-A). To terminate the modification process completely, the microwave-modified samples were immediately cooled to $0-1{ }^{\circ} \mathrm{C}$. Then, the obtained preparations were stored under refrigeration $\left(4-6{ }^{\circ} \mathrm{C}\right)$. Evaluation of selected physicochemical properties was carried out immediately after the completed modification and after 6 and 12 months of storage.

Electrophoretic analysis. According to the methods of Laemmli $(1970)^{28}$, the electrophoresis method was performed on $6 \%$ thickening polyacrylamide gel and $12.5 \%$ split polyacrylamide gel using a Hoefer Scientific Instruments SE-600 (San Francisco, USA) apparatus to assess oligomer formation. After electrophoresis, the gel was fixed for one hour in a solution consisting of $40 \%$ water, $50 \%$ methanol, and $10 \%$ acetic acid. The gel was then stained for $20 \mathrm{~h}$ in a $10 \%$ acetic acid solution with the addition of $0.25 \mathrm{~g}$ Coomassie Brilliant Blue R-250. The gels were scanned and stored as computer files. Next, densitometric analysis was performed using TotalLab Quant computer software by Nonlinear Dynamics Ltd. (United Kingdom, USA).

Hydrolytic activity. The hydrolytic activity was determined by the spectrophotometric method following the procedure of Leśnierowski et al. ${ }^{13}$. The activity was calculated using the difference in absorbance of the micrococcus suspension within $60 \mathrm{~s}$ after adding the sample at $\lambda=450 \mathrm{~nm}$ using a VSU2-P Carl Zeiss Jena spectrophotometer (Germany). Each sample was measured 5 times.

The results are presented as the residual hydrolytic activity (RHA), which was calculated as the percentage of the measured hydrolytic activity of modified LLC $\left(\mathrm{HA}_{\mathrm{L} 1}\right)$ to the hydrolytic activity of natural LLC $\left(\mathrm{HA}_{\mathrm{L} 0}\right)$

$$
\mathrm{RHA}=\left(\mathrm{HA}_{\mathrm{L} 1} / \mathrm{HA}_{\mathrm{L} 0}\right) * 100(\%)
$$

where $\mathrm{RHA}$ - is the residual hydrolytic activity, $\mathrm{HA}_{\mathrm{L} 1}$-is the hydrolytic activity of modified LLC, and $\mathrm{HA}_{\mathrm{L} 0}{ }^{-}$is the hydrolytic activity of unmodified LLC.

Surface hydrophobicity of modified lysozyme. The surface hydrophobicity was determined using the ligand agent polyoxyethylene sodium monooleate (Tween 80, SERVA, Germany).

This detergent prevents the Bio-Rad dye from binding to the lysozyme molecule by covering the protein with the hydrophobic site. The level of interference was measured by a spectrophotometer. According to the experimental procedure of Lieske and Konrad $(1994)^{29}, 0.1 \%$ lysozyme solution was diluted with phosphate buffer at $\mathrm{pH} 6.5$ for analysis.

There were four tubes marked a, b, a', and b' for each sample.

(1) test tube a: $50 \mu \mathrm{L}$ of lysozyme and $50 \mu \mathrm{L}$ of distilled water

(2) test tube a': $50 \mu \mathrm{L}$ of lysozyme and $50 \mu \mathrm{L}$ of Tween 80 solution

(3) test tube b: $100 \mu \mathrm{L}$ of distilled water

(4) test tube b': $50 \mu \mathrm{L}$ of distilled water and $50 \mu \mathrm{L}$ of Tween 80 solution 
Each of the test tubes was reacted with $2.5 \mathrm{~mL} 0.02 \%$ Bio-Rad dye solution for $16 \mathrm{~min}$, and then the absorbance was measured at $595 \mathrm{~nm}$ wavelength using a Carl Zeiss Jena VSU2-P spectrophotometer.

The surface hydrophobicity $(\mathrm{SH})$ of the modified lysozyme result was calculated according to the formula:

$$
\mathrm{SH}=\frac{[a-b]-\left[a^{\prime}-b^{\prime}\right]}{[a-b]} * 100 \%
$$

The difference in the surface hydrophobicity of the modified $\mathrm{SH}_{\mathrm{Li}}$ samples and the unmodified LLC sample $\mathrm{SH}_{\mathrm{L} 0}$ was presented as $\Delta \mathrm{SH}$.

$$
\Delta \mathrm{SH}=\mathrm{SH}_{\mathrm{Li}}-\mathrm{SH}_{\mathrm{L} 0}
$$

where $\Delta S H$ is the change in surface hydrophobicity, $\mathrm{SH}_{\mathrm{L} 0}$-is the native LLC surface hydrophobicity, and $\mathrm{SH}_{\mathrm{Li}}$ is the surface hydrophobicity of modified LLC for subsequent samples "i".

Colour test. The colour test was based on measurement of the extinction of the obtained preparations solutions and comparison of their size depending on the enzyme modification conditions. Measurements were carried out with the spectrophotometric method using the VSU2-P spectrophotometer by Carl Zeiss Jena (Germany). The test samples were diluted 100 times, and the measurement was carried out at a wavelength $\lambda$ of 450 $\mathrm{nm}$ in quartz cuvettes with an optical path length of $10.0 \mathrm{~mm}$.

Microbiological test. Both the LLC and microwave-modified enzymes were used in microbiological tests to compare their effectiveness against selected bacterial strains: Micrococcus luteus PCM 525 and gram-negative Escherichia coli PCM 2793, Proteus mirabilis PCM 1361, Pseudomonas fluorescens PCM 2123, and Pseudomonas fragi PCM 1856. They were provided by the Institute of Immunology and Experimental Therapy of the Polish Academy of Sciences (Wrocław, Poland). From 24-h cultures, bacterial suspensions were prepared in $0.85 \%$ $\mathrm{NaCl}$ medium (Biomérieux) at a density of 0.5 on the McFarland scale using a Densimat apparatus (Biomérieux). Then, $1 \mathrm{~mL}$ bacterial suspension dilution at $10^{4} \mathrm{cfu} / \mathrm{ml}$ was added to test tubes containing $4 \mathrm{~mL}$ broth and $5 \mathrm{~mL}$ prepared solutions of monomer or modified lysozyme. A solution of the required lysozyme concentration was prepared by dissolving lysozyme in sterile water. The test assessment of the antibacterial activity of various forms of lysozyme (unmodified LLC, obtained immediately after modification and modified and stored for 12 months) consisted in determining the threshold concentration of the enzyme at which:

1.Native lysozyme LLC no longer destroyed gram-negative bacteria, and the lysozyme obtained immediately after modification still showed such action.

2.Lysozyme obtained after modification immediately was no longer active against gram-negative bacteria, and the one stored for 12 months was still active.

Samples were incubated at $30^{\circ} \mathrm{C}$ or $37^{\circ} \mathrm{C}$ for $24 \mathrm{~h}$. After incubation with the classic flooding method, the presence of analysed bacteria was determined on culture media: Mannitol Salt Agar (CM 0085), Pseudomonas Agar Base CM 0559 supplemented with Pseudomonas CFC Selective Agar Supplement (SR 0103), Mc Conkey Agar CM 0115, MRS Agar (De Man, Rogosa, Sharpe), and Mc Conkey Agar CM 0115 (Oxoid). The control comprised samples with no lysozyme solutions.

Statistical analysis. All results were collected and analysed using SPSS 19.0 software, and the results are presented as the mean values with the standard error. Analysis of variance and post hoc analysis with the Tukey test and Kruskal-Wallis method were used to verify results with heterogeneity of variance. Each test was performed in quintuplicate.

Received: 2 March 2021; Accepted: 29 April 2021

Published online: 21 May 2021

\section{References}

1. Masschalck, B. \& Michiels, C. W. Antimicrobial properties of lysozyme in relation to foodborne vegetative bacteria. Crit. Rev. Microbiol. 29, 191-214 (2003).

2. Leśnierowski, G. Lysozyme and its modified forms: properties, potential for its production and application. In Handbook of Eggs in Human Function (eds Watson, R. R. \& Meester, F. D.) 483-496 (Wageningen Academic Publisher, Wageningen, 2015).

3. Ibrahim, H. R., Higashiguchi, S., Juneja, L. R., Kim, M. \& Yamamoto, T. A structural phase of heat-denatured lysozyme with novel antimicrobial action. J. Agric. Food Chem. 44, 1416-1423 (1996).

4. Leśnierowski, G. \& Yang, T. Lysozyme and its modified forms: A critical appraisal of selected properties and potential. Trends Food Sci. Technol. 107, 333-342. https://doi.org/10.1016/j.tifs.2020.11.004 (2021).

5. Takahashi, H. et al. Heat-denatured lysozyme inactivates murine norovirus as a surrogate human norovirus. Sci. Rep. 5, 11819 (2015).

6. Ibrahim, H. R., Thomas, U. \& Pellegrini, A. A helix-loop-helix peptide at the upper lip of the active site cleft of lysozyme confers potent antimicrobial activity with membrane permeabilization action. J. Biol. Chem. 276, 43767-43774 (2001).

7. Carrillo, W., García-ruiz, A., Recio, I. \& Moreno-arribas, M. V. Antibacterial activity of hen egg white lysozyme modified by heat and enzymatic treatments against oenological lactic acid bacteria and acetic acid bacteria. J. Food Prot. 77, 1732-1739. https://doi. org/10.4315/0362-028X.JFP-14-009 (2014).

8. Liu, H. et al. LYG1 exerts antitumor function through promoting the activation, proliferation, and function of CD4+ T cells. OncoImmunology 6, 1-12. https://doi.org/10.1080/2162402X.2017.1292195 (2017).

9. Acharya, D., Liu, G. \& Gack, M. U. Dysregulation of type I interferon responses in COVID-19. Nat. Rev. Immunol. 20, 397-398. https://doi.org/10.1038/s41577-020-0346-x (2020).

10. Shalhoub, S. Interferon beta-1b for COVID-19. The Lancet 2, 19-20. https://doi.org/10.1016/S0140-6736(20)31101-6 (2020). 
11. Yang, T. \& Leśnierowski, G. Changes in selected physicochemical properties of lysozyme modified with a new method using microwave field and oxidation. PLOS ONE 14(4-12), 2019. https://doi.org/10.1371/journal.pone.0213021 (2019).

12. Yang, T. \& Leśnierowski, G. Thermal modification of hen egg white lysozyme using microwave treatment. Acta Sci. Pol. Technol. Aliment. 19, 149-157 (2020).

13. Leśnierowski, G., Borowiak, R., Cegielska-Radziejewska, R. \& Stangierski, J. Resorcinol as protective agent in thermochemical modification of lysozyme. Food Technol. Biotechnol. 51, 410-413 (2013).

14. Leśnierowski, G. \& Cegielska-Radziejewska, R. Potential possibilities of production, modification and practical application of lysozyme. Acta Sci. Pol. Technol. Aliment. 11, 223-230 (2012).

15. Tomizawa, H., Yamada, H. \& Imoto, T. The mechanism of irreversible inactivation of lysozyme at $\mathrm{pH} 4$ and $100^{\circ} \mathrm{C}$. Biochemistry 33, 1332-1336 (1994).

16. Young, A. C. M., Tilton, R. F. \& Dewan, J. C. Thermal expansion of hen egg-white lysozyme. J. Mol. Biol. 235, 302-317 (1994).

17. Ibrahim, H. R., Aoki, T. \& Pellergini, A. Strategies for new antimicrobial proteins and peptides: Lysozyme and aprotinin as model molecules. Curr. Pharm. Des. 8, 671-693 (2002).

18. Thomas, B. R., Vrkilov, P. G. \& Rosenberger, F. Efects of microheterogeneity in hen egg white lysozyme crystallization. Acta Crystallogr. D 54, 226-236 (1998).

19. Leśnierowski, G. Physicochemical Methods for the Modification and Measurement of Lysozyme Activity 1-104 (Poznan University of Life Sciences in Poznań, Poznań, 2007).

20. Leśnierowski, G., Kijowski, J. \& Cegielska-Radziejewska, R. Ultrafiltration-modified chicken egg white lysozyme and its antibacterial action. Int. J. Food Sci. Technol. 44, 305-311. https://doi.org/10.1111/j.1365-2621.2008.01713.x (2009).

21. Ibrahim, H. R. On the novel catalytically-independent antimicrobial function of hen egg-white lysozyme: A conformation-dependent activity. Nahrung 42, 187-193 (1998).

22. Liu, J., Wang, N. \& Liu, Y. The antimicrobial spectrum of lysozyme broadened by reductive modification. Poultry Sci. 97, 3992-3999 (2018).

23. Carrillo, W., Lucio, A., Gaibor, J., Morales, D. \& Vásquez, G. Isolation of antibacterial hydrolysates from hen egg white lysozyme and identification of antibacterial peptides. J. Med. Food 21, 808-818 (2018).

24. Cegielska-Radziejewska, R., Leśnierowski, G., Szablewski, T. \& Kijowski, J. Physico-chemical properties and antibacterial activity of modified egg white-lysozyme. Eur. Food Res. Technol. 231, 959-964 (2010).

25. Vilcacundo, R. et al. Antibacterial activity of hen egg white lysozyme denatured by thermal and chemical treatments. Sci. Pharm. 86, 48 (2018).

26. Touch, V., Hayakawa, S. \& Saitoh, K. Relationships between conformational changes and antimicrobial activity of lysozyme upon reduction of its disulfide bonds. Food Chem. 84, 421-428 (2004).

27. Ibrahim, H. R., Matsuzaki, T. \& Aoki, T. Genetic evidence that antibacterial activity of lysozyme is independent of its catalytic function. FEBS Lett. 506, 27-32 (2001).

28. Laemmli, U. Cleavage of structural proteins during the assembly of the head of bacteriophage T4. Nature 227, 680-687 (1970).

29. Lieske, B. \& Konrad, G. A new approach to estimate surface hydrophobicity of proteins. Milchwissenschaft 49, 663-666 (1994).

\section{Author contributions}

G.L., R.CR. and T.Y. conceived the experiments; G.L., R.CR. and T.Y. conducted the experiments. G.L. and T.Y. analysed the results and prepared the figures; T.Y. and G.L. wrote the manuscript. G.L. supervised the research. All authors reviewed the manuscript.

\section{Competing interests}

The authors declare no competing interests.

\section{Additional information}

Correspondence and requests for materials should be addressed to G.L. or T.Y.

Reprints and permissions information is available at www.nature.com/reprints.

Publisher's note Springer Nature remains neutral with regard to jurisdictional claims in published maps and institutional affiliations.

Open Access This article is licensed under a Creative Commons Attribution 4.0 International License, which permits use, sharing, adaptation, distribution and reproduction in any medium or format, as long as you give appropriate credit to the original author(s) and the source, provide a link to the Creative Commons licence, and indicate if changes were made. The images or other third party material in this article are included in the article's Creative Commons licence, unless indicated otherwise in a credit line to the material. If material is not included in the article's Creative Commons licence and your intended use is not permitted by statutory regulation or exceeds the permitted use, you will need to obtain permission directly from the copyright holder. To view a copy of this licence, visit http://creativecommons.org/licenses/by/4.0/.

(C) The Author(s) 2021 